\title{
Reducción de la expansión de la prisión preventiva
}

\section{Reducing the Expansion of Preventive Prison}

\author{
Jhon Eber Cusi Rimache*
}

http://dx.doi.org/10.21503/lex.v15i20.1446

* Abogado por la Universidad Nacional de San Agustín, Arequipa. Maestrista en Ciencias Penales en la Universidad Nacional Mayor de San Marcos. Ponente en diversos certámenes académicos.

Correo electrónico: revistadecienciaspenales@gmail.com

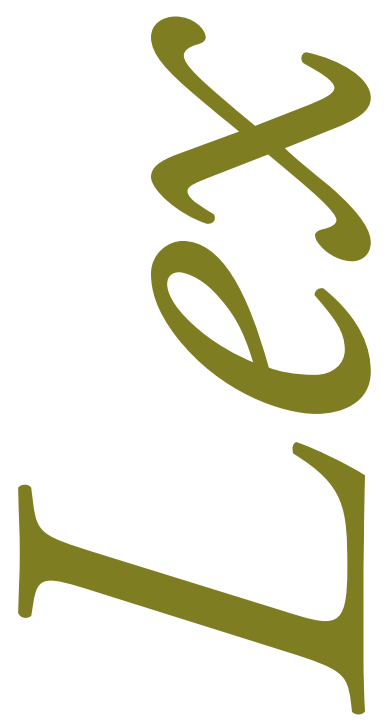

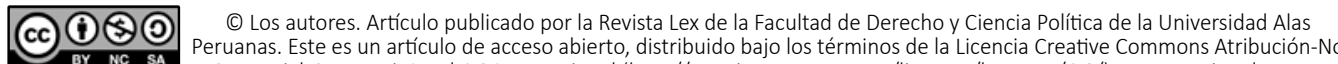
Comercial-Compartir Igual 4.0 Internacional.(http://creativecommons.org/licenses/by-nc-sa/4.0/), que permite el uso no comercial, distribución y reproducción en cualquier medio, siempre que la obra original sea debidamente citada. 


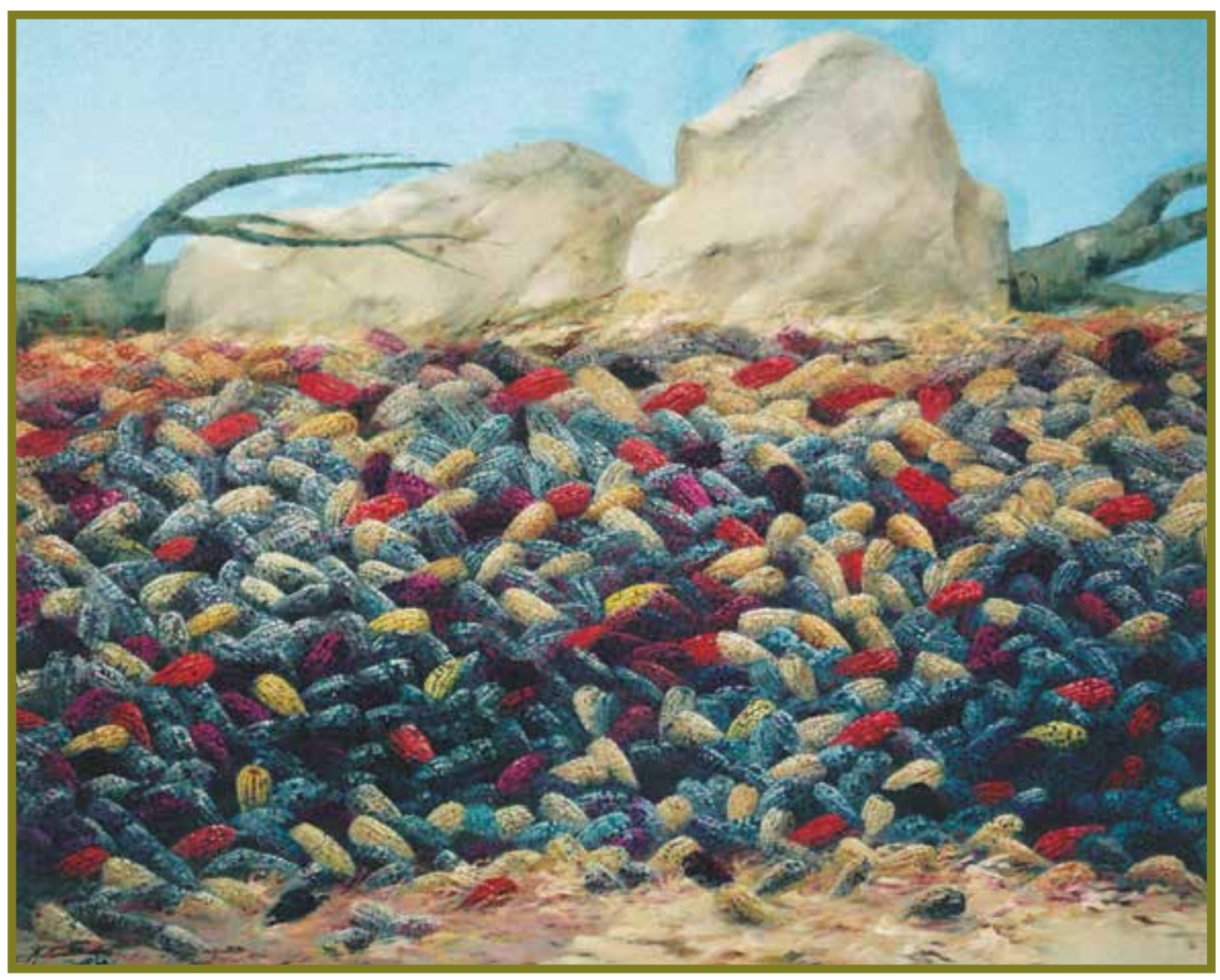

Raúl Cárdenas. Tiempo de cosecha. 180 x 150 cm. 


\section{RESUMEN}

Estar inmersos en la discusión de los problemas de la prisión preventiva nos abre las puertas para una cuestión no solo técnica sino también como enclave constitucional. Constitucionalmente solo son válidas las consecuencias jurídico-penales a partir de hechos mas no de presunciones; en tal sentido, se presenta el problema cuando se genera una consecuencia jurídica al evaluar el peligro procesal en un ambiente de presunción vulnerándose las normas claramente establecidas. Las presunciones abren una expansión por carecer de objetividad y hacer frente a esa expansión hasta poder hallar a una aplicación verdaderamente excepcional solo es con la exigencia de un análisis exhaustivo del peligro procesal. El peligro procesal no puede ser evaluado en el escenario presuntivo sino objetivo por el propio mandato de la norma (ver art. 268.c del CPP), al señalar que la advertencia del peligro de fuga y la obstaculización de los elementos de pruebas sean a partir de sus antecedentes u otras circunstancias.

Palabras clave: expansión, peligro procesal, peligro presuntivo, peligro real, ideología constitucional.

\section{ABSTRACT}

Being immersed in the discussion of the problems of preventive prison opens the door for a question not only technical but as a constitutional enclave. Legal criminal consequences are only constitutionally valid after facts and not after presumptions. In that sense, a problem arises when a legal consequence is applied when assessing the procedural risk considering presumptions breaking clearly established laws. The presumptions open a non-objective expansion and facing such expansion until finding a truly exceptional application is only achieved with a comprehensive analysis of the procedural risk. Procedural risk cannot be assessed on the basis of assumptions but of objectivity as stated by the law (article 268 of the Criminal Process Code) when appointing that escape risk and obstruction of pieces of evidence should be based on background and other circumstances.

Key words: expansion, procedural risk, presumptive risk, real risk, constitutional ideology. 


\section{INTRODUCCIÓN}

Hoy vivimos en la inmediatez, ${ }^{1}$ en el día a día individual (mientras no suframos el mal, el resto no importa), y nos es indiferente el proceso histórico en el cual se ha conquistado la libertad. Esta inmediatez limita tener una conciencia sobre determinados hechos históricos que dieron giro al derecho.

La vulneración de la libertad no es causa de indignación masiva en estos días porque corre por las venas el consumismo como causa de la inmediatez vivencial; por el contrario, es aplaudido en ciertas circunstancias. Esta vivencia colorida suele darse cuando la prisión preventiva prospera y las víctimas sienten el alivio por encontrar justicia, no importa si es legítimo. Solo se piensa en "enjaular" al imputado. La excesiva tecnificación y la poca humanización del aprendizaje permiten privar de la libertad de un imputado por razones extracautelares sin causar zozobra en la sociedad. Por el contrario, son aplaudidos, condecorados, ascendidos, héroes y respetados porque se entiende que se está realizando la justicia. Es una mera apariencia entendida como eficacia. Esta carencia hace colegir que la medida cautelar personal ${ }^{2}$ es asumida con mayor frecuencia en el proceso penal correspondiente sin mayor detenimiento en la excepcionalidad de la medida. La carencia del entendimiento del valor de la libertad habilita la utilización prima facie de la prisión preventiva cuando en verdad su manifestación debería ser de última ratio.

Es bien sabido que la libertad le otorga al ser humano la potestad de elegir, ser creativo y desarrollar de su personalidad. Pues, las personas que no cuentan con libertad no podrán elegir por sí mismos sino habrá una dependencia de aquellos que deciden por él, por ende no tendrá la integridad del desarrollo personal, tampoco entenderá el valor de la libertad; esto en otros términos significa que si vulneran la libertad de los demás para él será igual o entenderá que es normal. Y, en los términos que nos ocupa, el populismo cautelar entendido por quien

1 Cfr. David Garland, La cultura del control. Crimen y orden social en la sociedad moderna, traducción de Máximo Sozzo, primera edición (Barcelona: Gedisa, 2005), 32.

2 Cfr. Sebastián Soler, Bases ideológicas de la reforma penal (Buenos Aires: Editorial Universitaria, 1966), 32 y ss. 
acuña estas letras como expansión de la prisión preventiva siendo una especie de "justicia emocional o de poder". Esto expresado en términos constitucionales, evidentemente será violatorio porque no solo es una infracción a la excepcionalidad de la medida, la proporcionalidad de la medida cautelar, entre otros, sino es la afectación de un derecho fundamental: la libertad. Es decir, la prisión preventiva está verdaderamente sustentada en razones morales, populares, ideológicas, entre otras, que desplazan a las razones jurídicas que verdaderamente debería ser el fundamento de la medida cautelar. Un Estado democrático como el nuestro tiene que fundarse en el derecho, no en el temor; ${ }^{3}$ en las razones suficientes, no en las suposiciones; en los argumentos lógicos, no en las conjeturas; en pruebas legítimamente obtenidas y no en arbitrariedades; en el resguardo del debido proceso, no en el autoritarismo; en la libertad, no en su destrucción. En términos de Bacigalupo ${ }^{4}$, la función principal del Estado es la protección de la libertad.

Se suele pensar que la lucha contra la delincuencia será eficaz en tanto y en cuanto no se tengan muchas garantías a favor del imputado; sin embargo, la eficacia no se asienta en la ausencia de garantías ${ }^{5}$ sino en el cumplimiento, pues con ello se fortalece la institucionalidad y se legitima la decisión. Disminuir las garantías para la lucha eficaz de la delincuencia es un mito que conduce a la perversidad del poder punitivo en el Estado democrático. Un proceso penal sin garantías no es un proceso, sino aplicación de poder (sea económico, político, social, etc.) sobre el individuo. ${ }^{6}$ Una sentencia americana dice: "No por ser más duras vamos a lograr la justicia penal más eficaz". ${ }^{7}$ Somos veedores que a más penas o sentencias condenatorias es más el aumento delictivo, entonces esto ya fracasó como tantas posturas han pronunciado, y en la presente no se pretende hacerles competencia. El proceso penal es eficaz e intimidatorio en la medida que se cumplan las garantías, pues el propio Estado es capaz de cumplir sus propias reglas que ha emitido: es una inspiración de admiración y respeto. Pero si el Estado es el primero en no cumplir las reglas del juego que él mismo diseñó, entonces perderá la credibilidad y el poder mismo de sancionar (además de controlar) y se convertirá en ilegítimo.

En tal sentido, se tiene que tomar en cuenta que una norma no solo regula sino se expresa como garantía $^{8}$ de que, evidentemente, tiene que ser respetada no solo por el Estado sino por

\footnotetext{
Jorge Carpizo, Concepto de democracia y sistema de gobierno en América Latina, segunda edición (Lima: Idemsa, 2008), 118. Enrique Bacigalupo, El debido proceso penal (Madrid: Hammurabi, 2005), 47.

Cfr. James Reátegui Sánchez, En busca de la prisión preventiva, primera edición (Lima: Jurista editores, 2006), 40 y ss.

"Nuestra historia se encarga de demostrarnos sobradamente que los sistemas penales latinoamericanos no surgen en función de códigos o legislaciones, originarias o importadas, sino desde los tiempos de la primera colonización se presentan como un ejercicio de poder controlador disciplinario militarizado ejercido sobre las mayorías y sobre los disidentes". Para mayor abundamiento, ver Gabriela L. Gusis y Pablo D. Vega, "El encarcelamiento en América Latina: perspectivas y propuestas", en La medida del castigo. El deber de compensación por pena ilegales, dirigido por Eugenio Raúl Zaffaroni (Buenos Aires: Ediar, 2012), 57.

7 R. v. Gladue [1999] 1 SCR 688, 1999 CanLII 679 (SCC), ítem nº 46.

8 Max Ernst Mayer, Normas jurídicas y normas de cultura (Rechtsnormen und kulturnormen), traducción de José Luis Guzmán Dálbora (Buenos Aires: Hammurabi, 2000), 89 y ss.
} 
todos aquellos que son parte de ella. En suma, el Estado debe cumplir la norma que emite para hacer notar su institucionalidad y su rigurosidad en los procesos penales.

Pues, si únicamente se busca la eficacia del proceso penal sin tomar en cuenta las garantías, entonces solo se estará actuando con rabia, prepotencia, rencor, presión interna o externa haciendo gala de la expansión de la prisión preventiva que hará que se pierda la objetividad en la persecución del delito. El representante del Ministerio Público tiene una labor importante en la lucha contra el crimen, pero eso será posible cuando se actúe con la objetividad y seriedad, siempre en consonancia con el respeto de los derechos fundamentales del imputado, porque se debe tener en cuenta que se está juzgando a un ser humano. La norma adjetiva ha recogido el principio de objetividad de la actuación fiscal en el art. IV del TP del CPP, que dice: "El Ministerio Público está obligado a actuar con objetividad, indagando los hechos constitutivos de delito, los que determinen y acrediten la responsabilidad o inocencia del imputado...".

\section{EXPANSIÓN DE LA PRISIÓN PREVENTIVA}

En el proceso penal se ha vuelto casi normal la aplicación de la prisión preventiva siendo prima facie, pues se declara fundada la prisión preventiva en el proceso penal para investigar y poder encontrar alguna evidencia (del delito y la vinculación de esta con el imputado) mas no para cumplir la finalidad de evitación del peligro de fuga u obstaculización; y, si en el tiempo concedido no se pudo hallar prueba alguna que lo vincule al internado preventivo, entonces cabe la posibilidad de la prolongación de la prisión preventiva para seguir investigando y ver si se puede encontrar más pruebas que puedan incriminar al encausado, pero si a pesar de ello no hay una causa probable para juicio, igual tendrán que formular una acusación para ver qué sucede. Una especie del trato como enemigo al imputado en el proceso penal, pues esa forma de aplicación de la prisión preventiva genera desconfianza, repudio, rechazo, temor, etc. Solo conduce al agujero negro de la arbitrariedad.

Para nadie es novedad que una gran cantidad de los procesos penales siempre cargan con una prisión preventiva. Esto ocurre porque se enfoca la prisión preventiva desde la política criminal propio del derecho penal sustancial ${ }^{10}$ con cierta desesperación frente a la inseguridad ciudadana. Reátegui Sánchez al respeto indica que "uno de los aspectos de la expansión de la prisión preventiva es la politica penal de emergencia que en Latinoamérica se ha caracterizado como

9 “El verdadero enemigo de un proceso penal del Estado es la presencia dela Prisión preventiva”, véase James Reátegui Sánchez, En busca de la prisión preventiva..., 54.

10 "El hecho de considerar que el problema de la prisión preventiva no es un problema del derecho penal sino fundamentalmente del derecho procesal penal, no cambia en nada su esencia, pues no altera la naturaleza de la violencia, los barrotes no se transforman en otras cosas y las cárceles no se convierten automáticamente en lugares distintos. Por tal motivo, debe replantearse el problema de la prisión preventiva en el sentido que debe formar parte de la agenda del derecho penal material”, apuntado por James Reátegui Sánchez, En busca de la prisión preventiva..., 63. 
un desarrollo de la ideología de la seguridad nacional". ${ }^{11} \mathrm{Al}$ recurrirse prima facie hace entender que sirve para combatir la delincuencia, función propia del derecho penal sustancial.

La concepción adoptada en esto últimos días es que la prisión preventiva es la regla y como excepción la libertad, es decir, una expansión de la prisión preventiva. Esto no es fruto de la aplicación profesionalizada sino improvisada que desordena la institución cautelar y conduce a su deslegitimación. Esta anomalía puede obedecer a varios factores. Antiguamente existían más presos en las cárceles, esto no significa que habían muchos que cometían delitos o que era una sociedad bastante insegura, sino se creaba delitos para complacer a los fines del poder económico, así, la vagancia o delitos de poca monta con la sola finalidad de generar actividad laboral en la prisión con magros sueldos o simplemente, como fue en la época de la colonización, en ese tiempo eran internados para ser enviados a los pueblos colonizados para que puedan poblar a nombre del Estado que los llevaba, es decir, del colonizador o país dominante en ese entonces. Ahora, la expansión de la prisión preventiva se debe al afán de garantizar la seguridad social porque la inseguridad ha llegado a sus niveles más altos. En cambio, la prisión preventiva no tiene la finalidad de "garantizar la seguridad ciudadana" sino el éxito del proceso, pues aquel es propio del derecho penal material. La seguridad en la sociedad no se debe conducir con los programas penales que solo reprime sino con programas educativos de calidad, no solo almacenamiento de información cual sistema cibernético sino mucho más allá, con los valores y el ímpetu para transformar una sociedad mediante diversos mecanismos. $^{12}$

La prisión preventiva se ha entendido de manera errónea como una respuesta inmediata al delito, fundándose en la necesidad de la pena, ${ }^{13}$ pero esto tiene que ser excepcional porque si es entendido y aplicado por la necesidad de la pena para hacer parecer la eficacia de la justicia penal entonces habrá perseguido los fines del derecho penal mas no cautelar, siendo por ello ilegítimo. Pues internar a una persona vía prisión preventiva por un fundamento que no es propio de la naturaleza cautelar es desestabilizador ${ }^{14}$ del derecho cumbre del ser humano: la libertad.

11 James Reátegui Sánchez, En busca de la prisión preventiva..., 64. Las cursivas son nuestras.

12 Las personas nacemos con diversas habilidades, dones o tipo de inteligencia; y, en nuestro país simplemente no hacemos provecho y explotamos ello sino imponemos conocimiento o actividades que los inspira y solo realizarán por mero cumplimiento o ganar un sueldo. Hasta ahí se llega, pero la educación no se trata de eso sino de transformar una sociedad para bien potenciando las habilidades que cada ser humano tiene. Y una formación cargada de valores que en estos días solo queda de nombre.

13 Fernando Díaz Cantón, "Vicisitudes de la cuestión de la autonomía o dependencia entre el derecho penal y el derecho procesal penal", en Estudios sobre justicia penal, libro homenaje a Julio B. J. Maier (Buenos Aires: Editores del Puerto, 2005), 831.

14 Cfr. Fernando Díaz Cantón, "La relación entre la prueba y la coerción penal”, en Derecho procesal penal. La injerencia en los derechos fundamentales del imputado, tomo II, dirigido por Adgardo Alberto Donna, (Buenos Aires: Rubinzal-Culzoni Editores, 2006), 88. 
Tal es la expansión de la prisión preventiva que la decisión está centrada en la presunción del peligro de fuga y de obstaculización. Se presume que si espera una pena de cadena perpetua va a fugar o si está libre entonces ocultará, destruirá las pruebas, así como influenciará a los testigos o peritos. O por la sola pertenencia a una organización criminal ya se darán por cumplidos los presupuestos del peligro procesal de fuga. Estos presupuestos centrales y razón por las cuales existe esta figura de basta polémica no pueden presumirse sino tienen que ser concretos o dar los indicios racionales que permitan colegir que efectivamente ocurra ello. Siempre se debe partir de una base objetiva.

La expansión de la prisión preventiva nubla la recta administración de justicia en nuestros tribunales generando la inseguridad jurídica, ${ }^{15}$ produciendo también una jurisprudencia contraria al desarrollo jurídico, mermando así la legitimidad del derecho y la intervención jurídica penal por parte del Estado peruano. Además, debe entenderse que la prisión es un lugar alienante en donde las relaciones intersubjetivas son falseadas porque la prisión es mucho más que la privación de la libertad, pues es la entrada a un mundo artificial donde todo es negativo ${ }^{16}$ y así van generándose futuros delincuentes.

\section{FRENTE CONSTITUCIONAL PARA LA REDUCCIÓN DE LA PRISIÓN PREVENTIVA}

La prisión preventiva se encuentra en el Título III de la Sección III del Código Procesal Penal y tiene como finalidad privar el derecho a la libertad de tránsito del imputado dentro del proceso penal que se le sigue antes de la sentencia. Esta restricción tiene como objetivo hacer exitoso el proceso penal que se emprendió.

Esta privación afecta gravemente la libertad del imputado. Esta afectación será posible luego de una profunda evaluación de la existencia de los fundados y graves elementos de convicción que coligan la alta probabilidad del delito y la vinculación con el hecho punible como autor o partícipe, la certeza del peligro procesal, la proporcionalidad y duración de la medida.

En tal sentido, el Fiscal convencido de la alta probabilidad podrá requerir la prisión preventiva, y se realizará la audiencia correspondiente en el modo y forma que establece nuestro cuerpo adjetivo. Ahora, si el Juez estima declarar fundada la prisión preventiva requerida ten-

15 Cfr. Atilio Aníbal Alterini, La inseguridad jurídica (Buenos Aires: Abeledo-Perrot, 1993), 31 y ss. "La seguridad jurídica y la certeza jurídica solo pueden ponerse en práctica en la medida en que un Estado esté gobernado de acuerdo con reglas previamente anunciadas que sean claras e inteligibles en sí misma”; Neil Maccormick, Retórica y Estado de Derecho. Una teoría del razonamiento jurídico, traducido por José Ángel Gascón Salvador y revisado por Luis Vega de la Reñon (Lima: Palestra, 2016), 47.

16 Cfr. Louk Hulsman, Sistema penal y seguridad ciudadana. Hacia una alternativa, traducido por Sergio Politoff (Barcelona: Ariel, 1984), 50. 
drá que justificar la medida y será indispensable, excepcional y razonable para que el proceso penal pueda funcionar en orden a sus fines. ${ }^{17}$

La privación de la libertad debe estar fundada en derecho, ser motivada, proporcional, necesaria, y con elementos de convicción suficientes que permitan llegar a la alta probabilidad de la comisión del delito atribuido como autor o partícipe. Así, el tenor del art. 253 Inc. 2 del CPP dice: "La restricción de un derecho fundamental requiere expresa autorización legal, y se impondrá con el respeto al principio de proporcionalidad y siempre que, en la medida y exigencia necesaria, existan suficientes elementos de convicción”. Para emitir una autorización legal de la restricción tiene que ser necesaria, es decir, no exista otra vía igualmente satisfactoria a fin de tener la presencia del imputado durante el proceso.

La proporcionalidad de la medida exigida en la prisión preventiva no puede ser fugaz o simplemente mencionada cual recital memorizado sino que se tiene que operativizar en el caso concreto.

Neyra Flores ${ }^{18}$ señala que la prisión preventiva permite conocer la ideología del ordenamiento jurídico. Las normas en general tienen un respaldo ideológico de diversas razones que permitan, se entiende en materia penal, la protección de los bienes jurídicos encapullados en los tipos penales.

En esa línea, la ideología a veces no siempre responde a la protección real de los bienes jurídicos sino de manera escondida, encubierta a intereses difusos de diversos fines. La ideología en el derecho penal y, en especial en el procesal penal, tiene que ser el respeto de los derechos humanos y no políticos, morales, sociales, entre otros ajenos al derecho. La ideología constitucional solo tendrá luz en un Estado que exista una democracia consolidada donde se haga prevalecer la libertad, el valor y los principios. Sin embargo, eso no implica que un "culpable" sea escudado por la norma y evite una sanción penal, sino que sea juzgado con el resguardo de los derechos fundamentales. El juzgamiento con el respeto de las normas, siendo la garantía el cumplimiento cabal, y en consonancia con las normas constitucionales y convencionales tejerán un proceso legítimo; de no ser así, solo será una muestra de poder, de juzgamiento bajo la sombrilla del poder sin importar las normas (las garantías). La prisión preventiva tiene que emitirse en claro cumplimiento de la norma (garantía), con el sello indeleble de los principios y valores constitucionales; de lo contrario, solo será una manifestación de poder, por ende, ilegítimo.

17 Pedro J. Bertolino, "El modo de ejecutar las medidas de coerción personal como una hipótesis de injerencia en los derechos del imputado", en Derecho procesal penal. La injerencia en los derechos fundamentales del imputado, tomo I, dirigido por Edgardo Alberto Donna (Buenos Aires: Rubinzal- Culzoni Editores, 2006), 29 y ss.

18 José Antonio Neyra Flores, Manual del nuevo proceso penal \& de litigación oral (Lima: Idemsa, 2010), 509. 
Hacemos referencia a una ideología constitucional y no legal, pues como bien apunta el maestro arequipeño Mendoza Ayma, ${ }^{19}$ "el legalismo, como ideología, se caracteriza por ser una concepción estática y conservadora, aséptica y neutral”. Así, la evaluación legal de la prisión preventiva como ideología permitirá hacer un examen casi sin contenido, pues la ideología constitucional es la que verdaderamente llena de contenido a la ley que permite una verdadera interpretación restrictiva y garantista de la norma. En tal sentido, en la prisión preventiva no se puede solo tener una ideología legalista haciendo gala del bien conocido cumplimiento legal del art. 268 y ss. del CPP sino en plataforma de la ideología constitucional y hacer lucir un control de legitimidad. Siendo esto así, se cumplirá el abstractamente divulgado concepto de que la prisión preventiva es excepcional y será otorgado porque es indispensable y necesaria para el éxito del proceso penal. Con la interpretación desde los derechos constitucionales, principios y valores, la prisión preventiva tendrá una aplicación excepcional y no se recurrirá prima facie a ella para investigar al acusado sino como última opción.

Si la prisión preventiva es utilizada como primera opción, entonces estaremos más cerca de una manifestación radical demoledora del derecho a la libertad, y quedará aniquilado el principio de la excepcionalidad de la prisión preventiva. Esta cara radical es parafraseada por Reátegui Sánchez ${ }^{20}$ señalando que el verdadero derecho penal del enemigo es la presencia de la prisión preventiva. Se centra el proceso penal en un tribunal bélico en donde el Estado considera al imputado como malo, y él señala del mismo modo al Estado, pero como esta institución tiene poder sobre el ciudadano entonces actuará para destruirlo y mandarlo a prisión preventiva y hacerle entender a la sociedad que la lucha contra la inseguridad es eficaz.

Existe un uso excesivo de la prisión preventiva y la poca cultura de utilizar las medidas alternativas ${ }^{21}$ de la prisión preventiva, lo que desestabiliza la institución judicial. Este exceso es de variopinta razón: de carácter político, económico, social, la seguridad ciudadana, entre otras, sin importar el derecho del procesado. Solo castigar o hacer uso de la prisión preventiva para demostrar poder, no es constitucionalmente ético, pues se estaría combatiendo la delincuencia basándose en el dolor del delincuente. ${ }^{22}$ El uso excesivo desnaturaliza la medida cautelar personal porque puede seguir finalidades distintas a lo establecido. Garland ${ }^{23}$ señala que aún prevalece en la sociedad la urgencia de castigar por castigar. El apunte del autor ex-

19 Francisco Celis Mendoza Ayma, Presupuesto acusatorio, determinación e individualización de la pena, proceso penal. La medida del dolor, primera edición (Lima: Jurista Editores, 2015), 45.

20 James Reátegui Sánchez, En busca de la prisión preventiva..., 54.

21 E. García España y J. L. Diéz Ripollés, direct., Realidad y política penitenciarias (Málaga: Instituto andaluz interuniversitario de Criminología, Informe ODA 2010/2011, 2012), 234.

22 Francisco Celis Mendoza Ayma, Pretensión punitiva. La conformación del proceso, Nuevo Código Procesal Penal (Lima: Librerías San Bernardo, 2014), 76.

23 David Garland, Castigo y sociedad moderna. Un estudio de teoría social, primera edición en español (España: Siglo XXI Editores, 1999), 226. 
trapolado en la prisión preventiva tiene plena vigencia. Las prisiones preventivas se han vuelto una urgencia de privar la libertad por privar, no porque realmente concurran los presupuestos de la prisión preventiva sino porque se quiere hacer entender a la sociedad el funcionamiento efectivo de la administración de la justicia ${ }^{24}$ y darles la calma a los ciudadanos. Cuando en realidad eso no es así.

La prisionización preventiva se lleva a su máxima expresión a punta de arbitrariedades. La búsqueda de un control social utilizando la prisión preventiva para darle una tranquilidad a la sociedad desnaturaliza por completo la prisión preventiva como medida cautelar personal; incluso se puede afirmar un anticipo de sentencia condenatoria porque la sociedad cuando escucha que alguien fue internado a prisión ya piensa que es culpable, y cuando sale libre después de un debido proceso, la sociedad deslegitima la intervención de las instituciones, llámese Poder Judicial o Ministerio Público. En otros términos, las instituciones son mal vistas por la sociedad, y lo primero que se piensa es en la corrupción o la justicia del poder y no en el cumplimiento cabal de la ley por las instituciones encargadas de la administración de justicia. La CIDH mediante un Informe ${ }^{25}$ dijo que la mayor utilización de la prisión preventiva es para hacer ver cómo una solución al delito es una falacia que utiliza el poder político y se evade la responsabilidad de adoptar medidas preventivas y sociales más profundas que permitan vivir en una sociedad más tranquila, en donde los pobladores no estén con el temor de un asalto, de una violación, de la corrupción, evasión tributaria entre otros delitos que merman el buen despegue de desarrollo de nuestro país.

La privación de la libertad con otras finalidades que no sean cautelares solo desnaturalizan su esencia misma y mina la jurisprudencia como fuente de derecho, ${ }^{26}$ perjudicando la seguridad jurídica y la institucionalidad jurídica. Si bien nuestro Estado no se orienta por la jurisprudencia ${ }^{27}$ sino por la ley; sin embargo, tiene mucha referencia en los casos similares. La jurisprudencia en tanto sea emitida en el marco del respeto de los derechos humanos, principios rectores del derecho o en especial de las instituciones jurídicas que se aplican, generará más confianza y seguridad jurídica.

24 Se debe dejar en claro que no estamos en contra del real funcionamiento de la administración de la justica; es más, su funcionamiento eficaz es nuestro augurio, sino que debe llevarse con el respeto de los derechos fundamentales, evitando la arbitrariedad de la práctica jurídica a tal punto de que su existencia debe quedar en el olvido.

25 Informe sobre el uso de la prisión preventiva en las Américas, Organización de las Naciones Unidas-Comisión Interamericana de Derechos Humanos, OEA/Ser, L/V/II. Doc. 46/13, 30/12/2013, p. 120.

26 Cfr. Georg Rusche y Otto Kirchheimer, Pena y estructura social, traducido por Emilio García Méndez (Bogotá: Temis, 1984), 70.

27 Sin embargo, en la actualidad, los debates jurídicos en los tribunales se están reduciendo a la enumeración o citas innumerables de casos similares. La más conocida es la cita constante de criterios (mal adoptados) expuestos en los Acuerdos Plenarios. Si un magistrado escuchar citar jurisprudencia se le suele otorgar la razón no porque realmente sea correcta sino por evitar desfilar por los pasillos del OCMA. 
La CIDH ha mostrado su preocupación a través del Informe sobre la aplicación arbitraria e ilegal de la prisión preventiva; es un problema crónico. Se destaca la disfuncionalidad del sistema de justicia penal que a la vez es la causa de otros problemas como el hacinamiento y la falta de separación entre el proceso con prisión preventiva y los sentenciados. ${ }^{28}$

A consideración de la $\mathrm{CIDH},{ }^{29}$ la prisión preventiva no es una verdadera sanción; no constituye una medida punitiva, sino apenas precautoria y efímera. La prisión preventiva no puede tener una naturaleza sancionatoria, ni se entiende su internamiento sobre la base de la culpabilidad del encausado sino que solo tiene como fines legítimos prevenir la fuga del acusado o evitar que este interfiera con el desarrollo apropiado del proceso. ${ }^{30}$

Entonces solo se pretenderá racionalizar la prisión preventiva ${ }^{31}$ y hacer más justas las medidas cautelares teniendo siempre presente la libertad del encausado y presumir realmente su inocencia.

La prisión preventiva será amistosa con la presunción de inocencia si se cumple a cabalidad los presupuestos expuestos en el art. 268 y ss. del CPP. Además, serán justificadas a un nivel incuestionable la excepcionalidad y necesidad de la medida, y finalmente será acelerado el proceso a fin de no ser vulnerado su derecho a la libertad porque puede existir la posibilidad de que sea absuelto de los cargos atribuidos. La prisión preventiva se justificará en el caso concreto con la ponderación de los elementos de convicción que concurren. La prisión preventiva como medida cautelar no se determina solo por el delito que se imputa al procesado ${ }^{32}$ sino que se sustenta en la existencia real de otros presupuestos, ya que la inconcurrencia de cualquiera de ellos hace insustentable la internación del agente en prisión.

Por otro lado, la prisión preventiva no puede fundarse en los rasgos de personalidad del imputado sino en los hechos concretos que se presentan en la realidad, amparados con los fundados y graves elementos de convicción, pues el derecho penal despliega su contenido sobre la base de los hechos. Este es el centro principal en el proceso penal, ya como objeto de investigación, ya como objeto de prueba, ya como individualización del agente del delito, ya para determinar el título de imputación, etc. Así, pues, resulta crucial el hecho en el juicio penal. Entonces, la personalidad del encausado deberá ser rechazada porque implicará retro-

28 Informe sobre el uso de la prisión preventiva en las Américas, Organización de las Naciones Unidas-Comisión Interamericana de Derechos Humanos, OEA/Ser, L/V/II. Doc. 46/13, 30/12/2013.

29 Caso López Álvarez vs. Honduras, CIDH 01/02/2006, voto razonado del Juez García Ramírez, párrafo 18.

30 Informe sobre el uso de la prisión preventiva en las Américas, Organización de las Naciones Unidas-Comisión Interamericana de Derechos Humanos, OEA/Ser, L/V/II. Doc. 46/13, 30/12/2013, p. 9 y ss.

31 Cfr. Caso Chaparro Álvarez y Lapo Íniguez vs. Ecuador, CIDH, 21/11/2007, voto razonado del juez Sergio García Ramírez, párrafo 10 .

32 Para mayor abundamiento, ver Caso López Álvarez vs. Honduras, CIDH 01/02/2006, párrafo 81. 
ceder en el tiempo y devaluar el avance de las ciencias penales porque este tema cansadamente cuestionado y desechado en la discusión actual no puede ahora empoderarse cuando se discute la prisión preventiva para justificar los peligros procesales o materiales.

\section{EXHAUSTIVIDAD EN EL ANÁLISIS DEL PELIGRO PROCESAL}

Como bien se sabe, para la emisión de la prisión preventiva se requieren sendos presupuestos que deben ser analizados en una audiencia contradictoria. Los primeros son los fundados y graves elementos de convicción que determinan el delito y la autoría o participación del investigado; la prognosis de la pena y el peligro procesal. Este último es analizado solo en la medida de que los antes mencionados hayan sido plenamente satisfechos, pues el análisis no puede partir del peligro procesal.

El peligro procesal en la medida cautelar personal es vital ${ }^{33}$ y el peligro procesal (sea potencial o real) deberá ser objetivo, a diferencia de los fundados y graves elementos de convicción que serán hasta el grado de alta probabilidad mas no de certeza porque ello implicaría realizar un juicio de culpabilidad. Esto debido a que por más que existan los presupuestos materiales de la prisión preventiva, tales como los graves y fundados elementos de convicción, la prognosis de la pena y la pertenencia a una organización criminal. No podrá emitirse válida y legítimamente la prisión preventiva si no se cumple el peligro procesal, peligro de fuga principalmente u obstaculización de los elementos de prueba.

En otros términos, el que decide si hay mérito para fundar una prisión preventiva o no es el peligro procesal y la proporcionalidad de la medida; en la presente me enfocaré solo en el peligro procesal. Éste debe ser analizado con la rigurosidad en cada caso concreto, es el centro, el meollo, la matriz, la médula de la prisión preventiva. Pues, las causales del peligro procesal, tales como el peligro de fuga y la obstaculización de los elementos de prueba obedecen a una lógica cautelar en el proceso penal. ${ }^{34}$

Por esta razón, la explicación del presupuesto procesal en la resolución que dicta la prisión preventiva tiene que basarse en datos objetivos y no sospechas subjetivas porque si en la prisión preventiva no se toma en cuenta seriamente el peligro de fuga o la obstaculización de los elementos de prueba, entonces solo se estará otorgando la prisión preventiva en función al cumplimiento de los presupuestos materiales, generalmente por la apariencia del delito y su probable pena, y con ello, evidentemente, se habrá realizado un juzgamiento del imputado en una etapa que no corresponde. Si no hay evaluación meticulosa de los presupuestos del peligro procesal como eje central en la medida cautelar, entonces se habrá juzgado.

33 Cfr. Fernando Díaz Cantón, "La relación entre la prueba y la coerción penal”..., 138.

34 Cristian Riego y Mauricio Duce, Prisión preventiva y reforma procesal penal en América Latina. Evaluación y perspectiva (Chile: Centro de Estudios de Justicia de las Américas - CEJA, 2008), 26. 
La falta de objetividad y de evidencia suficiente del peligro procesal en la emisión de la prisión preventiva será arbitraria. ${ }^{35}$ En tal sentido, se tiene que tener en cuenta que el peligro procesal no es la gravedad de la conducta delictiva ni la dimensión de la sanción penal, ${ }^{36}$ sino la burla al proceso, y, en tanto no eluda la acción de la justicia o intente maniobrar los elementos de prueba, no será razonable declarar fundada la prisión preventiva.

El peligro procesal es nuclear en la emisión de la prisión preventiva. Así, la sentencia de la Corte Suprema ${ }^{37}$ dijo: "el peligro procesal (...) es el elemento más importante para valorar en un auto de prisión preventiva”. Pues cuando el peligro procesal es mínimo en el proceso, el fin de aseguramiento no sirve como base para una intromisión tan severa ${ }^{38}$ como es la prisión preventiva. Precisamente la frontera de la excepcionalidad se pasará porque el peligro procesal está plenamente satisfecho, de no ser así, se estará desnaturalizando.

El peligro procesal será debidamente motivado por el titular de la acción penal, y no tendrá que ser supuesta ${ }^{39}$ sino objetiva, que, por cierto, en nada afectará la presunción de inocencia. No cabe duda, entonces, que el peligro procesal como requisito de la prisión preventiva es la determinación razonable del peligro de fuga ${ }^{40} \mathrm{o}$ la averiguación de la verdad.

El peligro procesal es uno de los más destacados y determinantes en la evaluación para la emisión o no de la prisión preventiva, y tiene que ser real y probado; de no ser así, la prisión preventiva recae en injustificada y manifiesta arbitrariedad. El peligro procesal es el presupuesto fuerza para justificar un encarcelamiento preventivo. ${ }^{41}$ Pero, el que determina con mayor sustento es el peligro de fuga porque esto manifiesta la rebeldía o la no sujeción del procesado al proceso que se le sigue.

Si la prisión preventiva se funda en otros temas que no tienen en su centro de discusión los peligros procesales, entonces la desnaturalización es completa y se pervierte el derecho.

35 En sentido similar, Elky Villegas Paiva, La detención y la prisión preventiva en el Nuevo Código Procesal Penal, primera edición (Lima: Gaceta Penal, 2013), 144 y ss.

36 Cfr. Segundo Mariano Montoya Calle, Peligro procesal y proceso debido (Lima: Editorial San Marcos, 2010), 236.

37 Sala Penal Transitoria, Casación 631-2015, Arequipa, 21/12/2015, Juez ponente San Martín Castro, considerando cuarto. En sentido similar, la STC N 1567-2002-HC/TC, 05/08/2002, cuyo fundamento 5 dice: "Por ello, la única manera de determinar si la detención judicial preventiva de un individuo no responde a una decisión arbitraria del juez, pasa por la observancia de determinados elementos objetivos que permitan concluir que, más allá de que existan indicios o medios probatorios que vinculan razonablemente al inculpado con la comisión del hecho delictivo y más allá del quantum de la eventual pena a imponerse, existe peligro de fuga o peligro de entorpecimiento de la actividad probatoria”.

38 Fernando Díaz Cantón, "La relación entre la prueba y la coerción penal”..., 90 y ss.

39 Sala Penal Transitoria, Casación 631-2015, Arequipa, 21/12/2015, Juez ponente San Martín Castro, considerando noveno. Así también, "el riesgo o peligro procesal invocado para dictar la medida cautelar esté fundado en circunstancias objetivas"; para mayor detalle ver Alberto Bovino y Paola Bigliani, Encarcelamiento preventivo y estándares del sistema interamericano (Buenos Aires: Editores del Puerto, 2008), 25.

40 Fernando Díaz Cantón, "La relación entre la prueba y la coerción penal”..., 135.

41 Reátegui Sánchez, En busca de la prisión preventiva...,192. 
Entonces, al centrar el foco de discusión solo en la prognosis de la pena, la apariencia del derecho, la pertenencia a una organización criminal y entre otros ajenos al peligro de fuga y obstaculización probatoria o con fines no cautelares, entonces será un grave atentado a los derechos fundamentales de los ciudadanos, en especial al trato digno y de inocente del imputado.

Las prisiones preventivas centradas en el peligro procesal y justificadas debidamente en los demás presupuestos son y serán el reflejo real de la excepcionalidad legitimada; ahora, si no ocurre eso, entonces, el caos y la crisis de esta figura darán luces a un cataclismo que llevará a los derroteros de las posturas abolicionistas.

Ahora, los peligros procesales no tendrán que ser evaluadas en un contexto de la estigmatización. Me explico, en la actualidad la economía ha tomado por asalto al derecho en general. En palabras de Morello, el mercado se aposentó y hace prevalecer sus reglas, ${ }^{42}$ pues en la evaluación de la prisión preventiva no tendría por qué influir la condición económica, el estatus social sino la conducta desplegada antes y durante el proceso a partir de la presunta conducta punible. Las personas no pueden ser estigmatizadas por indicadores de pobreza o riqueza; por ejemplo, no se debe ver a los pobres con malos ojos o ya culpables por la sola condición y a los que gozan de cierta riqueza exentos o incapaces de realizar un delito, lo que evidentemente no es así, porque tal vez son los que más cometen delitos pero de una manera más profesionalizada y poco torpe; "el pobre" no tiene vivienda para acreditar arraigo; por otro lado, "el rico", por el propio recurso que tiene, podría fugar o pervertir los elementos de prueba porque tiene recursos. En esa línea, los motivos en la prisión preventiva no podrán sostener estigmatizaciones sino fundamentos jurídicos del peligro procesal.

Si la demora del proceso es el fundamento de la prisión preventiva, entonces el error se lleva a dimensiones de desolación y deslegitimación del proceso penal y la medida preventiva. Todo procesado tiene derecho a ser juzgado dentro de un plazo razonable, y este plazo no depende del juzgado o investigado sino de la capacidad del Estado de realizar un proceso justo en un tiempo que amerita la complejidad del delito o del proceso. Distinta es la situación si el imputado es declarado contumaz o ausente; el primero puede ser un indicio para justificar eventualmente una prisión preventiva, a diferencia del ausente, que no tiene conocimiento del proceso que se le sigue; pero en nada se relaciona con el peligro en la demora o periculum in mora en estricto.

En el proceso penal no se puede argüir la prisión preventiva en base al peligro en la demora sino sobre la base del peligro de fuga o la obstaculización probatoria y los demás presupuestos. Entender como fundamento el peligro en la demora hace que se pierda el plazo razonable cuando se está con la prisión preventiva. No es lo mismo hablar de plazo razonable en un

42 Augusto M. Morello, La eficacia del proceso, segunda edición ampliada (Buenos Aires, Hammurabi, 2001), 803. 
proceso sin prisión preventiva y con prisión preventiva. Pues, como se ha explicado, se tiene que tomar en serio la libertad y la dignidad del ser humano; dicho en otros términos, el plazo razonable con prisión preventiva tiene que ser aún más serio porque se tiene encarcelado a un inocente.

Si el proceso es con prisión preventiva, entonces tendrá el Estado que acelerar la investigación (como una excepción a la investigación regular por tratarse de la libertad) o el juicio, porque si bien la norma prevé un plazo, se tiene que tomar muy en serio el derecho al plazo razonable, la libertad y la dignidad. Si el caso no requiere una cantidad exorbitante de búsqueda de pruebas y solo son algunas en colaboración interinstitucional, se podría acelerar entonces el plazo, y de manera colateral se respetará la libertad del ser humano y la presunción de inocencia; pero no se propone acelerar por acelerar sino siempre buscando la pulcritud en la administración de justicia para vivir en una sociedad realmente democrática; es democrática si se respetan los derechos fundamentales, especialmente el debido proceso y la siempre prevalencia del derecho a la libertad.

Por otro lado, las negligencias o carencias de eficacia con garantía en los procesos penales hacen que estos sean suplidos por el imputado, es decir, los riesgos no pueden ser asumidos por el imputado sino por el Estado. ${ }^{43}$ Es el Estado el anfitrión en el proceso penal que tiene que prever todos los riesgos, como por ejemplo proteger a los testigos, contar con especialistas para concurrir en la brevedad posible a la escena del crimen y no perder ninguna pesquisa o elemento que permita realizar una investigación seria.

En tal sentido, el peligro en la demora no sería una justificación para emitir prisión preventiva, afectaría claramente al derecho a ser juzgado en un plazo razonable del proceso penal con prisión preventiva. El peligro en la demora puede tener varias razones, por ejemplo, la complejidad. Pero, como reitero, el Estado tiene el deber de garantizar que cualquier imputado sea juzgado en la prontitud posible, siendo aún más rigurosa cuando el imputado está con prisión preventiva. La duración del proceso definitivamente no puede ser fundamento si no se consideran los presupuestos que establece la norma procesal y la Casación de Moquegua: proporcionalidad y duración de la medida.

\subsection{Clases de peligro}

\subsubsection{Peligro presunto}

Nuestra normativa apunta el peligro presunto. El art. 269 Inc. 2 del CPP reza: "la gravedad de la pena que se espera como resultado del procedimiento". Bajo esta literalidad, el titular de la acción penal incrementa el poder punitivo traducido en la mayor cantidad de

43 Cfr. Reátegui Sánchez, En busca de la prisión preventiva..., 185. 
años como probable pena a imponerse al acusado. Entonces, si la eventual pena es de cadena perpetua, entonces aparentemente cumpliría con el tenor legal apuntado y se dará por sentado el acatamiento del presupuesto y por tanto cubierto el peligro procesal de fuga.

Considero que esta forma de concepción denigra la dignidad y el derecho a ser tratado como inocente durante el proceso. Si por la cuantía de los años presumen in malam partem entonces el encausado es tratado como delincuente o responsable porque ya se está asegurando que se escapará y no asumirá su responsabilidad penal. Las inferencias parten de bases objetivas, y se debe contar con los indicios probados de peligro.

Además, la excepcionalidad de la medida corre riesgo al tener presente la presunción del peligro. Este principio permite la última medida cautelar gravosa como es la prisión preventiva, esto porque hay una variedad de medida que puede también asegurar la presencia o evitar el entorpecimiento en la recolección o actividad de la prueba.

La presunción del peligro consiente que la prisión preventiva sea la primera medida a recurrir y no la última, como exige su propia naturaleza de la medida cautelar personal. Para una cabal realización y resguardo del principio de excepcionalidad, creemos que debe extirparse del ordenamiento procesal el art. 269 Inc. 2 del CPP.

La presunción de peligro es una grave amenaza a la libertad, deslegitima la intervención del derecho penal, mina el derecho a la libertad, la presunción de inocencia, se empodera la arbitrariedad. Arbitrariedad que no solo hace cuerpo en la prisión preventiva sino incluso a la hora de la decisión en la sentencia.

\subsubsection{Peligro real}

La conducta de los hombres se traduce en hechos ${ }^{44} \mathrm{y}$ a partir de estos se determinan las consecuencias jurídicas en el proceso. La conducta del acusado es sumamente importante en el proceso penal para determinar las secuelas de su actuar. Estos son objetos de investigación, debate y de prueba en juicio, y, en específico, en la prisión preventiva también son valorados. Los hechos siempre serán valorados, y las presunciones, desterradas.

Ahora, el peligro real tiene que presentarse a través de conductas elusivas de la acción penal o que han obstruido, modificado, ocultado, suprimido, falsificado elementos de prueba, o han influenciado en la versión de los que tendrán participación en el proceso.

En la adopción de la prisión preventiva se evalúa el peligro real; de lo contrario, pasamos al escenario del ya comentado peligro presunto. Es decir, los peligros procesales tienen que

44 Atilio Aníbal Alterini, La inseguridad jurídica..., 18. 
estar plenamente probados en el caso concreto, ${ }^{45}$ no pueden ser solo sospecha porque eso implicaría privar la libertad en base a una "sospecha procesal". La acreditación del peligro procesal será en grado de certeza. La prisión preventiva tiene fundamento en el peligro procesal, además de la apariencia del derecho y la proporcionalidad de la medida.

La sospecha abre la puerta grande para la arbitrariedad, socava los derechos fundamentales y mina la evolución de la jurisprudencia. Frente a ello, el trabajo del Juez se vuelve más minucioso porque en la resolución que emite se tiene que identificar los inicios probados respecto al peligro procesal. El peligro procesal encuentra pleno respaldo y justificación ${ }^{46}$ en los indicios ofertados por el Fiscal.

En tal sentido, la Corte ${ }^{47}$ ha manifestado:

Dentro de los criterios que el Juez debe tener en cuenta para determinar el peligro de fuga están aquellos vinculados a la situación personal, familiar y económica del imputado, conocido como "arraigo" -que tiene esencialmente un carácter objetivo, y ni puede afirmarse con criterios abstractos, sino debe de analizarse conforme al caso concreto (artículo $269^{\circ} \mathrm{del}$ Nuevo Código Procesal Penal).

En fin, el peligro procesal en correspondencia con los indicios justifica con mayor solidez y objetividad, alejando a la presunción en la decisión de la prisión preventiva. Las inferencias son de hechos probados, no presumidos.

\section{APUNTES FINALES}

La institución cautelar personal — prisión preventiva — tiene una discusión de voluptuoso calibre, ya de su legitimidad, ya de los presupuestos, ya de la imputación concreta, etc., pero en esta ocasión solo se ha centrado en una expansión de la prisión preventiva causada por la excesiva presunción en el peligro procesal. Los hechos (acreditados) generan consecuencias jurídicas, las presunciones no. En cambio, en una suerte de querer enjaular rápidamente a los investigados se ha permitido la presunción del peligro procesal. El mismo por el propio tenor de la norma requiere ser evaluado. Así, la norma en su art. 286. C dice "que el imputado, en razón a sus antecedentes y otras circunstancias del caso particular, permite colegir razonablemente que trata de eludir la acción de la justicia y obstaculización de la averiguación de la

45 Cfr. Reátegui Sánchez, En busca de la prisión preventiva..., 195. "El juez debe estimar los medios suficientes, a disposición del imputado, para perpetrar la fuga”, en César San Martín Castro, Derecho procesal penal. Lecciones conforme el Código Procesal Penal de 2004 (Lima: Inpeccp y Cenales, 2015), 460.

46 Cfr. José Luis Embris Vásquez y Juan David Pastrana Verdejo, "La prisión preventiva y su función frente a la pena privativa de libertad en México", en Arraigo y prisión preventiva. Doctrina, legislación, jurisprudencia y formularios (México: Flores Editor y Distribuidor, 2010), 211.

47 Sala Penal Transitoria, Casación 631-2015, Arequipa, 21/12/2015, Juez ponente San Martín Castro, considerando tercero. 
verdad". Es clara la norma, al decir "de sus antecedentes y otras circunstancias"; por ende, la evaluación del peligro procesal no puede ser en un ámbito de la presunción sino en un grado de objetividad.

Esta objetividad en el análisis de la prisión preventiva, en específico del peligro procesal, hace frente a una expansión de la prisión preventiva. Obviamente, la expansión no solo obedece a la carencia de objetividad del peligro procesal sino también a otros factores que coadyuvan.

\section{REFERENCIAS}

- Alterini, Atilio Aníbal. La inseguridad jurídica. Buenos Aires: Abeledo-Perrot, 1993.

- Bacigalupo, Enrique. El debido proceso penal. Madrid: Hammurabi, 2005.

- Bertolino, Pedro J. "El modo de ejecutar las medidas de coerción personal como una hipótesis de injerencia en los derechos del imputado". En Derecho procesal penal. La injerencia en los derechos fundamentales del imputado. Tomo I. Dirigido por Edgardo Alberto Donna. Buenos Aires: Rubinzal- Culzoni Editores, 2006.

- Bovino, Alberto y Paola Bigliani. Encarcelamiento preventivo y estándares del sistema interamericano. Buenos Aires: Editores del Puerto, 2008.

- Carpizo, Jorge. Concepto de democracia y sistema de gobierno en América Latina. Segunda edición. Lima: Idemsa, 2008.

- Díaz Cantón, Fernando. "La relación entre la prueba y la coerción penal". En Derecho procesal penal. La injerencia en los derechos fundamentales del imputado. Tomo II. Dirigido por Adgardo Alberto Donna. Buenos Aires: Rubinzal-Culzoni Editores, 2006.

"Vicisitudes de la cuestión de la autonomía o dependencia entre el derecho penal y el derecho procesal penal". En Estudios sobre justicia penal. Libro homenaje a Julio B. J. Maier. Buenos Aires: Editores del Puerto, 2005.

- Embris Vásquez, José Luis y Juan David Pastrana Berdejo. "La prisión preventiva y su función frente a la pena privativa de libertad en México". En Arraigo y prisión preventiva. Doctrina, legislación, jurisprudencia y formularios. México: Flores Editor y Distribuidor, 2010.

- García España, E. y J. L. Diéz Ripollés, direct. Realidad y política penitenciarias. Málaga: Instituto andaluz interuniversitario de Criminología, Informe ODA 2010/2011, 2012. 
- Garland, David. La cultura del control. Crimen y orden social en la sociedad moderna. Traducción de Máximo Sozzo. Primera edición. Barcelona: Gedisa, 2005.

Castigo y sociedad moderna. Un estudio de teoría social. Primera edición en español. España: Siglo XXI Editores, 1999.

- Gusis, Gabriela L. y Pablo D. Vega. "El encarcelamiento en América Latina: perspectivas y propuestas”. En La medida del castigo. El deber de compensación por pena ilegales, dirigido por Eugenio Raúl Zaffaroni. Buenos Aires: Ediar, 2012.

- Hulsman, Louk. Sistema penal y seguridad ciudadana. Hacia una alternativa. Traducido por Sergio Politoff. Barcelona: Ariel, 1984.

- Maccormick, Neil. Retórica y Estado de Derecho. Una teoría del razonamiento jurídico. Traducido por José Ángel Gascón Salvador y revisado por Luis Vega de la Reñon. Lima: Palestra, 2016.

- Mayer, Max Ernst. Normas jurídicas y normas de cultura (Rechtsnormen und kulturnormen). Traducción de José Luis Guzmán Dálbora. Buenos Aires: Hammurabi, 2000.

- Mendoza Ayma, Francisco Celis. Pretensión punitiva. La conformación del proceso, Nuevo Código Procesal Penal. Lima: Librerías San Bernardo, 2014.

Presupuesto acusatorio, determinación e individualización de la pena, proceso penal. La medida del dolor. Primera edición. Lima: Jurista Editores, 2015.

- Montoya Calle, Segundo Mariano. Peligro procesal y proceso debido. Lima: Editorial San Marcos, 2010.

- Morello, Augusto M. La eficacia del proceso. Segunda edición ampliada. Buenos Aires, Hammurabi, 2001.

- Neyra Flores, José Antonio. Manual del nuevo proceso penal \& de litigación oral. Lima: Idemsa, 2010.

- Reátegui Sánchez, James. En busca de la prisión preventiva. Primera edición. Lima: Jurista editores, 2006.

- Riego, Cristian y Mauricio Duce. Prisión preventiva y reforma procesal penal en América Latina. Evaluación y perspectiva. Chile: Centro de Estudios de Justicia de las Américas CEJA, 2008.

- Rusche, Georg y Otto Kirchheimer. Pena y estructura social. Traducido por Emilio García Méndez. Bogotá: Temis, 1984. 
- San Martín Castro, César. Derecho procesal penal. Lecciones conforme el Código Procesal Penal de 2004. Lima: Inpeccp y Cenales, 2015.

- Soler, Sebastián. Bases ideológicas de la reforma penal. Buenos Aires: Editorial Universitaria, 1966.

- Villegas Paiva, Elky. La detención y la prisión preventiva en el Nuevo Código Procesal Penal. Primera edición. Lima: Gaceta Penal, 2013.

\section{JURISPRUDENCIA}

- Caso Chaparro Álvarez y Lapo Íniguez vs. Ecuador. CIDH, 21/11/2007. Voto razonado del juez Sergio García Ramírez.

- Caso López Álvarez vs. Honduras. CIDH 01/02/2006. Voto razonado del Juez García Ramírez.

- Sala Penal Transitoria. Casación 631-2015, Arequipa, 21/12/2015. Juez ponente San Martín Castro.

- STC Nº 1567-2002-HC/TC, 05/08/2002. 


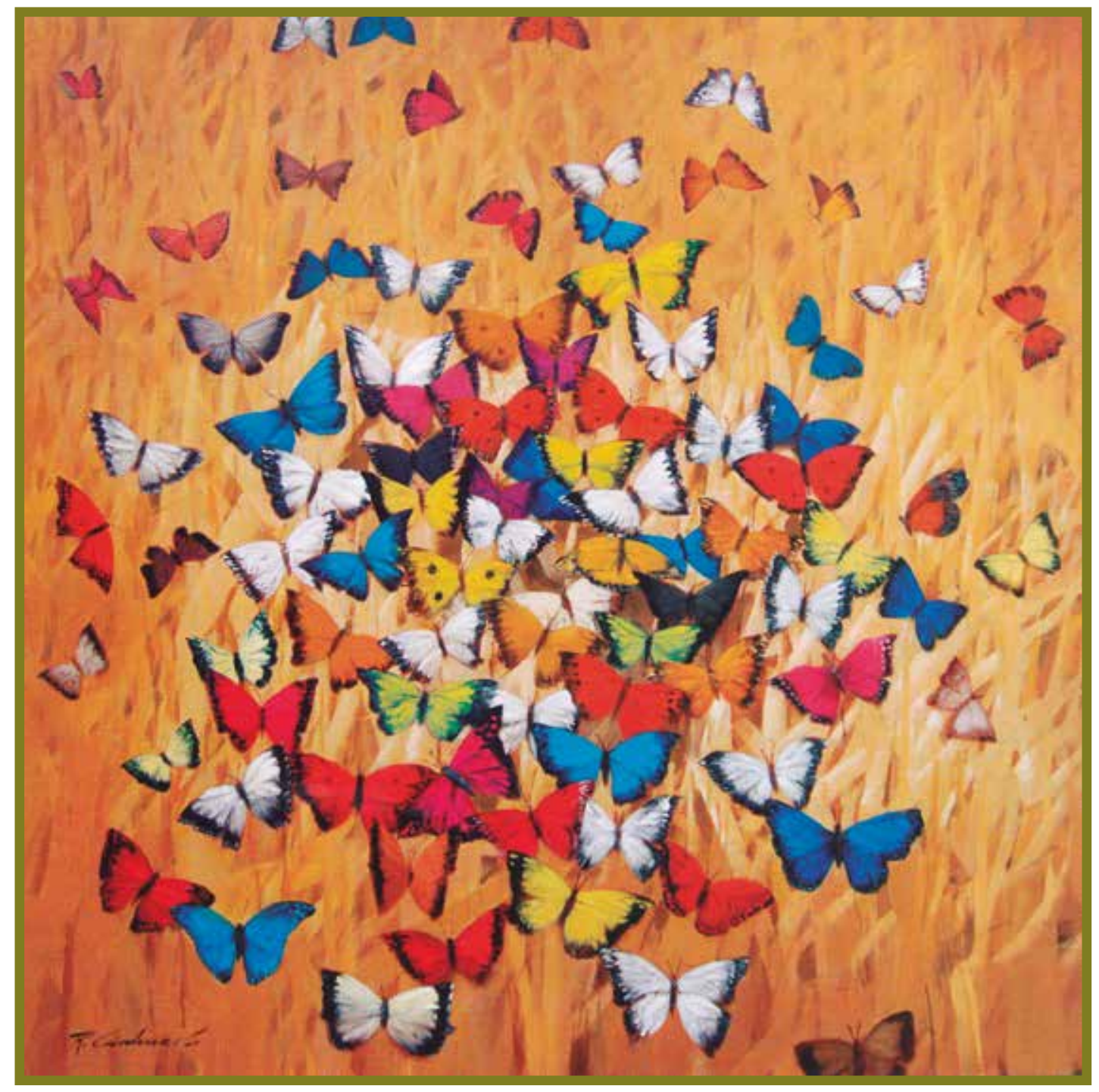

Raúl Cárdenas. Estio (de Estaciones). 150 x $150 \mathrm{~cm}$. 